\title{
Use of the Health History as a Psychiatric Screening Tool
}

\author{
Douglas Post, PbD, and Karl Miller, $M D$
}

Background: Numerous studies indicate that most mental health services are provided in the primary care medical setting and that problems exist with misdiagnoses and lack of recognition of mental health disorders. The purpose of our investigation was to determine whether patient responses on a typical medical health history form could be used to predict depression or anxiety.

Methods: New adult patients at a university community family practice clinic were surveyed during a 6-month period. Study patients completed a health history form and standardized inventories of anxiety and depression.

Results: The study sample included 187 patients. Positive responses to mood-related symptoms reported on the health history best predicted anxiety and depression. Nonmood symptoms were also significant, although not as powerful, predictors of these disorders. A significant relation existed between total number of positive symptoms and psychiatric diagnoses, which continued when mood symptoms were removed from the analyses. Results were used to develop physical, nonmood primary care symptom profiles that could be used to screen for anxiety and depression.

Conclusion: Providing physicians the means to improve mental health diagnostics can help advance patient care and health care system outcomes. (J Am Board Fam Pract 1998;11:452-8.)

It is commonly recognized that most mental health services in the United States are provided in the primary care medical setting, ${ }^{1-4}$ and an estimated 1 of 4 patients in the primary care medical setting have a psychiatric diagnosis. ${ }^{5}$ Of those currently suffering from a mental disorder, more than one half receive treatment in the outpatient medical sector and do not see a mental health professional. ${ }^{6}$ Primary care medicine has been labeled the de facto mental health system. ${ }^{7}$

Generally, research studies have indicated that detection of mental health disorders in the primary care setting is deficient. In reviewing the literature in this area, Higgins ${ }^{8}$ suggested that approximately one half of patients have a psychiatric disorder that is unrecognized and therefore untreated.

Explanations for these findings are varied. Three fourths of patients with a mental disorder complain to their physicians of primarily physical

Submitted, revised, 8 May 1998.

From the Department of Family Medicine, The Ohio State University, Columbus, and the Department of Family Medicine, The University of Tennessee, Memphis. Address reprint requests to Douglas Post, $\mathrm{PhD}$, Department of Family Medicine, The Ohio State University, Rardin Family Practice Center, 2231 North High St, Columbus, OH 43201.

This study was supported by a grant from the Ohio Academy of Family Physicians Foundation. symptoms. ${ }^{9}$ The average time spent on each patient in the primary care office encounter is 15 to 20 minutes. The wide variety of assessments, treatments, and paperwork managed during this time can be a barrier to the more time-consuming aspects of mental health assessment. ${ }^{10}$ Finally, a patient's focus on somatic complaints in a timeconstrained office encounter can impede the accurate diagnosis of mental health disorders.

Considering these factors, it follows that detection rates of mental disorders in primary care can be improved by examining the relation between patients' physical complaints and a mental disorder. Several studies have examined this issue and have arrived at similar conclusions.

Simon and VonKorff ${ }^{11}$ analyzed data from the National Institute of Mental Health Epidemiologic Catchment Area study on psychiatric morbidity and health service utilization. They found that psychologic distress was positively and significantly related to functional somatic symptoms as defined by the Diagnostic and Statistical Manual of Mental Disorders (DSM-IV). ${ }^{12}$ In an investigation of high users of medical services, Katon and colleagues ${ }^{13}$ suggested that somatization was likewise related to depressive and anxiety disorders as well as to self-reported disability. This line of research was later extended to an examination of personal- 
ity variables. Results indicated that past psychiatric disorders, primarily depression and anxiety, as well as the personality factor of harm avoidance, were independently and significantly related to somatization. ${ }^{14}$

Kroenke and colleagues ${ }^{15}$ have also examined relations between physical symptoms and mental health in the primary care setting. In one study results again suggested a strong association between physical symptoms and mental health. Physical symptoms were derived by using PRIME-MD, ${ }^{16}$ a psychiatric screening tool to establish mood, anxiety, alcohol, and somatoform disorders, and the physician administering the tool determined whether somatization was associated with positive symptoms reported by the patient. In their study, depression or anxiety was most likely if the patient reported a somatizing symptom, less likely if a particular symptom was present but not functionally somatic, and even less likely if no particular symptom was reported. Overall the number of symptoms, rather than a specific type of symptom, was the strongest predictor of psychiatric disturbance, indicating that frequency of physical symptomatology can be used as a mental health screening tool.

In a second study an attempt was made to describe specific predictors of depressive and anxiety disorders in an attempt to sort out high-risk patients for physician tracking. ${ }^{17}$ Symptom frequency from PRIME-MD was once more validated as an indicator. Other predictive factors included recent stress, self-rated health status, and symptom severity. Investigators found that patients seldom reported chief complaints of an emotional nature or offered a psychologic interpretation of their symptoms.

Further delineation of the relation between symptoms and a mental disorder can yield beneficial results in terms of improved detection and treatment. An ongoing dilemma in primary care practice is time management. PRIME-MD is a mental health screening tool that takes an average of 8.4 minutes to administer. Previously cited studies have used the Diagnostic Interview Schedule (DIS) as their data-gathering tool, an instrument that is more time intensive and that was designed for use by psychiatrists rather than primary care physicians. ${ }^{11,13,14}$

The health history form completed by the patient before the medical office visit is a quicker and
Table 1. Symptoms Relating to Anxiety and Depression.

Anxiety Symptoms

Depression Symptoms

Annoyed by little things

Aching muscles or joints

Chest pains

Constipation

Back or shoukler pains

Desired psychiatric help

Chest pains

Difficulty relaxing

Difficulty swallowing

Dizzy spells

Faintness

Frequent headaches

Frightening dreams or thoughts

Heartburn

High blood pressure

Itching or burning skin

Loose bowels

Loses temper

Nausea

Neck pains

Nervous with strangers

More than 6 cups coffee or tea per day

Racing heart

Shortness of breath

Sleeping difficulties

Sweating, night sweats

Considered suicide

Cries often

Desired psychiatric help

Difficulties in making decisions

Exhausted or fatigued

Dislikes criticism

Frequent headaches

Gained or lost more than $10 \mathrm{lb}$

Hopeless outlook

Lack of concentration or memory

Lonely or depressed

Loses temper

Loss of interest in eating

Sexual difficulties

Shy or sensitive

Sleeping difficulties

Stomach pains

Two or more alcoholic drinks per day

Trembles

Uses sleeping pills, marijuana, tranquilizers

Worries a lot

more typically used form for data collection of the patient's medical problems. Also, rather than focusing on a limited number of symptoms common to primary care or a group of symptoms related to somatization, the health history form is more comprehensive in its review of systems.

This investigation was designed to answer two questions: (1) what is the relation between patient responses on a health history and certain mental health disorders that are common in primary care, namely, anxiety and depression; and (2) do certain specific relations exist between particular physical symptoms and anxiety and depression? In other words, can physical symptom profiles be created that can be used by the busy primary care physician to screen for anxiety and depression? 


\section{Methods}

The subjects for the study were all new adult patients who attended a Midwestern family practice center during a 6-month period from July through December 1995. The center is an outpatient facility that provides a full range of family practice including obstetric care, laboratory services, and radiology facilities. This facility is located in a university community setting with an emphasis on providing medical care for that community. The practice consisted of both faculty and resident patients from all age groups. Fifty percent had private medical insurance, 25 percent were on public support, and 25 percent were selfpaying. All new patients were given the opportunity after informed consent to participate in the study. Those who agreed to participate were asked to complete three screening instruments. Patients were excluded if they decided not to participate in the study or did not complete all three instruments.

The Milcom Health History Form is a standard medical history form that covers 135 wideranging medical, lifestyle, and mood symptoms, as well as basic demographic information. Before starting the study, the co-principal investigators (a psychologist and family physician) met to decide which of the 135 symptoms listed on the Milcom form related to anxiety and depressive disorders. Reducing the number of symptoms was designed to increase the ratio between the numbers of study patients and numbers of variables. We concluded that 26 symptoms related to anxiety and 21 to depression (Table 1). The final study sample, which consisted of 187 patients, resulted in a subject-tovariable ratio of approximately 4 to 1 .

Patients in the sample also completed the Beck Depression Inventory (BDI), ${ }_{18}$ a 21 -item self-report measure to assess levels of depression, and the Beck Anxiety Inventory (BAI), ${ }^{19}$ a 21 -item tool to assess levels of anxiety. Both instruments are scored on a scale ranging from minimal (none to very little), to mild, moderate, and severe.

Initially we examined the correlations between the following demographic characteristics of the sample and depression and anxiety: sex, age, marital status, years of education, and family histories of alcoholism and "nervous breakdown" (a term listed on the Milcom form). We then used factor analysis to determine group clustering of the 47 anxiety and depression symptoms. The factors
Table 2. Percentages of Study Patients With Beck Anxiety Inventory (BAI) and Beck Depression Inventory (BDI) Severity Scores.

\begin{tabular}{lrr}
\hline Score & BAI & BDI \\
\hline Minimal & 60 & 66 \\
Mild & 21 & 21 \\
Moderate & 14 & 9 \\
Severe & 5 & 4 \\
Total & 100 & 100 \\
\hline
\end{tabular}

were used to form composite variables that were a straight sum of the symptoms comprising them. A varimax rotation was used in the analysis. Eigenvalues greater than 1.0 served as cutoff points in the factor analysis. Internal consistency was determined by calculating a Cronbach $\alpha$ for each factor.

After the factor analysis, stepwise linear multiple regression was used to determine which factors, symptoms, and demographics best predicted patient's scores on depression and anxiety measures. A stepwise discriminant analysis helped detect the best predictors of patients' minimal, mild, moderate, and severe levels of anxiety and depression. These results were then used to determine the relation between patients' actual placement in minimal, mild, moderate, and severe categories and their predicted classification based on the discriminant analysis.

Using multiple regression techniques and oneway analysis of variance (ANOVA), we explored the relation between symptom frequency and anxiety and depression. Initially, we examined the relation between all 135 Milcom symptoms and anxiety and depression, then we removed moodrelated symptoms on the health history form from the analyses, and using multiple regression, studied the relation between physical symptoms and anxiety and depression. The results led to the development of physical symptom profiles as potential predictors of anxiety and depression.

\section{Results}

During the study period, 360 new patients were seen in the family practice center. Of this group, 250 agreed to participate, and the 187 who completed all three forms made up the study sample. These patients had a mean age of 33 years and an average of 14 years of education. They were primarily female (69 percent), and nearly one half (48 percent) were single. Family histories of alco- 
Table 3. Results of Factor Analysis of Symptoms Important to Analysis of Anxiety and Depression, by Factor and Cronbach $\alpha$.

\begin{tabular}{|c|c|}
\hline $\begin{array}{l}\text { Factor and } \\
\text { Cronbach } \alpha\end{array}$ & Symptom \\
\hline Factor $1, \alpha=.82$ & $\begin{array}{l}\text { Cries often } \\
\text { Difficulty making decisions } \\
\text { Dislikes criticism } \\
\text { Frightening dreams or thoughts } \\
\text { Hopeless outlook } \\
\text { Lack of concentration or memory } \\
\text { Lonely or depressed } \\
\text { Nervous with strangers } \\
\text { Shy or sensitive } \\
\text { Worries a lot }\end{array}$ \\
\hline Factor $2, \alpha=.69$ & $\begin{array}{l}\text { Dizzy } \\
\text { Faintness } \\
\text { Headaches }\end{array}$ \\
\hline Factor $3, \alpha=.68$ & $\begin{array}{l}\text { Difficulty relaxing } \\
\text { Exhausted } \\
\text { Sleeping difficulties }\end{array}$ \\
\hline Factor $4, \alpha=.52$ & $\begin{array}{l}\text { High blood pressure } \\
\text { Racing heart } \\
\text { Trembles }\end{array}$ \\
\hline Factor $5, \alpha=.66$ & $\begin{array}{l}\text { Aching muscles } \\
\text { Back pains } \\
\text { Neck pains }\end{array}$ \\
\hline Factor $6, \alpha=.56$ & $\begin{array}{l}\text { Shortness of breath } \\
\text { Sweating } \\
\text { Weight gain or loss }\end{array}$ \\
\hline Factor $7, \alpha=.59$ & $\begin{array}{l}\text { Decreased eating interest } \\
\text { Annoyed by little things } \\
\text { Loses temper }\end{array}$ \\
\hline Factor 8 & Difficulty swallowing \\
\hline Factor $9, \alpha=.59$ & $\begin{array}{l}\text { Nausea } \\
\text { Stomach pains }\end{array}$ \\
\hline
\end{tabular}

holism in the father were reported by 11.8 percent and in the mother by 4.3 percent. Patients in the sample reported a family history of "nervous breakdown" in 1.1 percent of their fathers and 3.7 percent of their mothers. This sample is approximately 10 years younger and slightly more educated than the entire pool of the family practice center patients.

$\mathrm{BAI}$ and BDI scores were categorized by levels of severity. Table 2 displays percentages of the sample scoring in each category. In assessing the relation between demographic factors and anxiety or depression, correlational analysis revealed that both anxiety $(r=-.24, P<0.01)$ and depression $(r=$
$-.16, P<0.03$ ) were significantly related to years of education. Patients with lower levels of education were more likely to be depressed or anxious.

Chi-square analysis indicated only two demographic factors significantly related to depression. Patients who had less than 12 years of education $(\mathrm{F}=17.99, d f=6, P<0.01)$ and those who had an alcoholic parent $(\mathrm{F}=8.69, d f=3, P<0.03$ ) were more likely to be in a more severely depressed group. No demographic factors were significantly related to anxiety. Chi-square analysis also showed a significant relation between the depression and anxiety measures $(\mathrm{F}=97.88, d f=9$, $P<0.01$ ).

The factor analysis of the Milcom symptoms revealed 14 factors, the first 9 of which are important to later analyses. The symptoms in factors 1 through 9 and the respective Cronbach $\alpha$ are displayed in Table 3 . The analysis indicated that factor 1 (mood-related symptoms) accounted for a high percentage of the variance $(20.3$, compared with 7.4 for the next highest value) in anxiety and depression scores and possessed a high eigenvalue (8.51 compared with 3.09 for the next highest value) relative to all other factors.

Table 4 lists the factors and demographic variables that best predicted patients' anxiety and depression scores. Factor 1 was by far the strongest predictor. To examine which factors and demographic characteristics best predicted severity categories of minimal, mild, moderate, and severe, a stepwise discriminant analysis was performed on the data. Four variables were entered into the equation for anxiety, and 65 percent of the cases were correctly classified. Three variables were entered for depression, and 69 percent were correctly classified.

Table. 4 Stepwise Multiple Linear Regression Analysis Using Beck Anxiety Inventory (BAI) and Beck Depression Inventory (BDI) as Dependent Variables.

\begin{tabular}{|c|c|c|c|}
\hline \multicolumn{2}{|c|}{ pendent Variable } & \multicolumn{2}{|c|}{ BDI as Dependent Variable } \\
\hline Step & $\mathrm{R}^{2}$ & Step & $\mathrm{R}^{2}$ \\
\hline 1. Factor 1 & .41 & 1. Factor 1 & .55 \\
\hline 2. Factor 2 & .53 & 2. Factor 3 & .61 \\
\hline 3. Factor 6 & .59 & 3. Factor 8 & .62 \\
\hline 4. Factor 9 & .62 & 4. Alcoholism father & .64 \\
\hline 5. Factor 4 & .64 & $\begin{array}{l}\text { 5. Nervous breakdown } \\
\text { mother } \\
\text { 6. Factor } 9\end{array}$ & .66 \\
\hline
\end{tabular}


Table 5. Actual and Predicted Study Group Membership for Beck Anxiety Inventory and Beck Depression Inventory Classifications.

\begin{tabular}{|c|c|c|c|c|c|}
\hline \multirow[b]{2}{*}{ Group Classification } & \multirow{2}{*}{$\begin{array}{l}\text { No. of } \\
\text { Cases }\end{array}$} & \multicolumn{4}{|c|}{ Percent Predicted Group Membership } \\
\hline & & Minimal & Mild & Moderate & Severe \\
\hline \multicolumn{6}{|l|}{ Beck Anxiety Inventory } \\
\hline Minimal & 112 & 77.7 & 16.1 & 6.3 & 0.0 \\
\hline Mild & 39 & 30.8 & 46.2 & 12.8 & 10.3 \\
\hline Moderate & 26 & 7.7 & 30.8 & 34.6 & 26.9 \\
\hline Severe & 10 & 0.0 & 20.0 & 10.0 & 70.0 \\
\hline \multicolumn{6}{|c|}{ Beck Depression Inventory } \\
\hline Minimal & 125 & 74.4 & 16.8 & 8.0 & 0.8 \\
\hline Mild & 38 & 34.2 & 55.3 & 7.9 & 2.6 \\
\hline Moderate & 16 & 25.0 & 6.3 & 50.0 & 18.8 \\
\hline Severe & 8 & 0.0 & 0.0 & 12.5 & 87.5 \\
\hline
\end{tabular}

Table 5 lists the relation between actual group membership of patients derived from their Beck scores and their predicted group membership based on the discriminant analysis.

One-way ANOVA revealed that the number of symptoms (from a total of 135) was significantly related to a psychiatric diagnosis (BAI: $\mathrm{F}=57.31$, $d f=3, P<0.01$; BDI: $\mathrm{F}=39.93, d f=3, P<0.01)$. A relation also existed between number of symptoms and severity of anxiety and depression. As severity heightened, the mean number of symptoms reported on the health history also increased (Table 6).

For anxiety, all groups were significantly different from one another, with the exception of the moderate and severe groups. For depression, the mild and moderate groups were not significantly different, but all others were.

The final phase of the analysis examined the relation between physical, nonmood symptoms and anxiety and depression by removing the factor 1 mood cluster. When these symptoms were discarded from the analysis, number of symptoms continued to be significantly related to anxiety and depression (BAI: $r=.67, P<0.00$; BDI: $r=$ $.57, P<0.01)$.

Multiple regression techniques were then used to specify the amount of variance in anxiety and depression scores accounted for by each nonmood factor. Factor 2 accounted for 0.35 of the variance in anxiety scores. Factors 3, 4, 6, and 9 and the symptom of itching or burning skin accounted for an additional 0.21 of the variance. Factor 3 accounted for 0.35 of the variance in depression scores. Factors 8, 2, and 12 accounted for an additional 0.13 of the variance.

These results were used to detect the strongest symptom predictors of anxiety and depression. Multiple regression techniques found 8 anxiety-related and 5 depression-related symptoms. This analysis led to the development of nonmood physical symptom profiles that could be used to predict the presence and severity of anxiety and depression.

The nonmood physical symptom profile for anxiety included the following symptoms: trembles (3), difficulty relaxing (2), stomach pains (2), more sweating, night sweats (2), gained or lost more than 10 pounds, sleeping difficulties, frequent headaches, dizzy spells. Symptoms had unequal weights for anxiety, as listed in the parentheses next to the symptom. A weighted total of symptoms could then be used to predict severity of anxiety, with a score of 0 to 2 symptoms corresponding to minimal anxiety, 3 to 5 to mild anxiety, 5 to 7 to moderate anxiety, and 7 to 13 to severe anxiety.

A nonmood physical symptom profile for depression included the following symptoms: difficulty relaxing, sexual difficulties, exhaustion, dif-

Table 6. Relation Between Number of Symptoms and Severity of Anxiety and Depression.

\begin{tabular}{lcc}
\hline Level & $\begin{array}{c}\text { Number of } \\
\text { Anxiety Symptoms }\end{array}$ & $\begin{array}{c}\text { Number of } \\
\text { Depression Symptoms }\end{array}$ \\
\hline Minimal & 13 & 15 \\
Mild & 25 & 27 \\
Moderate & 35 & 33 \\
Severe & 43 & 49 \\
\hline
\end{tabular}


ficulty swallowing, and dizzy spells. Symptoms had equal weights in their relation to depression severity, so that the higher the number of symptoms, the more likely the patient was to be severely depressed. A symptom score of 0 to 1 corresponded to minimal depression, 1 to 2 to mild depression, 2 to 3 to moderate depression, and a 3 to 5 to severe depression.

\section{Discussion}

When patients focus on somatic complaints during a time-constrained office encounter, they can obstruct mental health assessment and treatment by primary care physicians. Missed diagnoses can result in highly negative outcomes for the patient, their family, their work, their community, and the system that provides care for them. This study explored using patient responses on a typical health history form as a means of improving detection of depression and anxiety disorders in primary care medical settings, as well as assessing how patient reports of medically related symptoms are related to levels of anxiety and depression.

Results of our study suggested that responses on a health history can be useful predictors of anxiety and depression. Not surprisingly, positive responses to mood-related symptoms best predicted the presence and severity of anxiety and depression. Mood-related questions are characteristic of the psychiatric screening tests promoted by several researchers to enhance detection rates for mental health disorders. ${ }^{20-22}$ Further analyses implied that physical symptoms reported on a health history could be used for the same purpose. Results confirmed the outcome of a variety of studies validating the use of symptom frequency as a psychiatric screening indicator. Our study extends this literature through use of the health history form, rather than PRIME-MD or the DIS, as a source of data.

Earlier studies have proposed that the total number of symptoms, not specific symptom types, is the most useful indicator of psychiatric disorders. ${ }^{15,17}$ In our investigation, responses by primary care patients to a health history symptom checklist led to the development of distinct primary care physical symptom profiles as potential predictors of anxiety and depression. For example, complaints of stomach pains and trembling suggested that patients might be experiencing moderate to severe anxiety. Complaints of difficulty swallowing and dizzy spells suggested the possibility of mild to moderate depression. These results can enable primary care physicians to expand their differential diagnoses when patients complain of a combination of physical symptoms related to the profiles developed in this study.

Results of this investigation are well-suited to the nature of the primary care setting. Physicians typically examine health histories before a patient visit, compared with administering psychiatric inventories or using structured inventories, both of which can be time-consuming. Furthermore, patients might be more prone to report complaints in a valid fashion on a health history form than they would on a psychiatric screening inventory, because of the stigma associated with emotional difficulties.

Limitations of the study include sample size, the collection of data, and to some degree the pilot nature of the project. Many of the patients were either unwilling to participate in the study or failed to complete all three forms. The resulting small sample size means this study might not be generalizable to a larger population. Also, we did not design this study to assess DSM-IV somatization patterns or measure health outcomes, such as disability or health status.

Another potential limitation of this study is that the patients were selected from a universitybased practice. Previous bias suggests a difference between the teaching-based practices and private practices. Nevertheless, a recent study has found no difference in clinical content when comparing family practice residency education centers with private family physicians' offices. ${ }^{23}$

Future studies with a larger population could further validate using the health history as a psychiatric screening tool to help increase detection of two conditions that have unfortunate societal consequences. The relation between detection and health outcome is complex and also merits further study. ${ }^{24,25}$

Providing physicians with the means to improve diagnostic skills in a manner well-suited to both the physical complaints that patients bring to the encounter and the somatic nature of physician training can advance patient care and health care system outcomes. Using the results of this study could lead to earlier assessment and improved treatment of mental health disorders in the setting where they are most often encountered. 


\section{References}

1. Gonzales JJ, Magruder KM, Keith SJ. Mental disorders in primary care services: an update. Publ Heath Rep 1994;109:251-8.

2. Barrett JE, Barrett JA, Oxman TE, Gerber PD. The prevalence of psychiatric disorders in a primary care practice. Arch Gen Psychiatry 1988;45:1100-6.

3. Regier DA, Narrow WE, Rae DS, Manderscheid RW, Locke BZ, Goodwin SK. The de facto US mental and addictive service system. Epidemiologic catchment area prospective 1-year prevalence rates of disorders and services. Arch Gen Psychiatry 1993; 50:85-94.

4. Katon W. The epidemiology of depression in medical care. Int J Psychiatry Med 1987;17:93-112.

5. Schulberg HC, Burns BJ. Mental disorders in primary care: epidemiologic, diagnostic, and treatment research directions. Gen Hosp Psychiatry 1988;10: 79-87.

6. Leon AC, Olfson M, Broadhead WE, Barrett JE, Blacklow RS, Keller MB, et al. Prevalence of mental disorders in primary care. Implications for screening. Arch Fam Med 1995;4:857-61.

7. Regier DA, Goldberg ID, Taube, CA. The de facto US mental health services system: a public health perspective. Arch Gen Psychiatry 1978;35:685-93.

8. Higgins ES. A review of unrecognized mental illness in primary care. Prevalence, nature, history and efforts to change the course. Arch Fam Med 1994;3: 908-17.

9. Schurman RA, Kramer PD, Mitchell JB. The hidden mental health network. Treatment of mental illness by nonpsychiatrist physicians. Arch Gen Psychiatry 1985;42:89-94.

10. Glasser $M$, Stearns JA. Unrecognized mental illness in primary care. Another day and another duty in the life of a primary care physician. Arch Fam Med 1994;3:862-4.

11. Simon GE, VonKorff $M$. Somatization and psychiatric disorder in the NIMH Epidemiologic Catchment Area Study. Am J Psychiatry 1991;148:1494-500.

12. Diagnostic and statistical manual of mental disorders (DSM-IV). 4th ed. Washingrton, DC: American Psychiatric Association, 1994.

13. Katon W, Lin E, VonKorff $M$, Russo J, Lipscomb $P$, Bush T. Somatization: a spectrum of severity. Am J
Psychiatry 1991;148:34-40.

14. Russo J, Katon W, Sullivan M, Clark M, Buckwald D. Severity of somatization and its relationship to psychiatric disorders and personality. Psychosomatics 1994;35:546-56.

15. Kroenke K, Spitzer RL, Williams JB, Linzer M, Hahn SR, deGruy FV, et al. Physical symptoms in primary care. Predictors of psychiatric disorders and functional impairment. Arch Fam Med 1994;3:774-9.

16. Spitzer RL, Williams JB, Kroenke K, Linzer M, deGruy FV, Hahn SR, et al. Utility of a new procedure for diagnosing mental health disorders in primary care. The PRIME-MD 1000 study. JAMA 1994;272: 1749-56.

17. Kroenke K, Jackson JL, Chamberlin J. Depressive and anxiety disorders in patients presenting with physical complaints: clinical predictors and outcome. Am J Med 1997;103:339-47.

18. Beck AT, Ward C, Mendelson M, Mock J, Erbaugh J. An inventory for measuring depression. Arch Gen Psychiatry 1961;4:561-71.

19. Beck AT, Epstein N, Brown G, Steer RA. An inventory for measuring clinical anxiety: psychometric properties. J Consult Clin Psychol 1988;56:893-7.

20. Callahn EJ, Bertakis KD, Azari R, Helms LJ, Robbins J, Miller J. Depression in primary care: patient factors that influence recognition. Fam Med 1997; 29:172.

21. Perez-Stable EJ, Miranda J, Munoz RF, Ying YW. Depression in medical outpatients. Underrecognition and misdiagnosis. Arch Intern Med 1990;150: 1083-8.

22. Kavan MG, Pace TM, Ponterotto JG, Barone EJ. Screening for depression: use of patient questionnaires. Am Fam Physician 1990;41:897-904.

23. Gilchrist V, Miller RS, Gillanders WR, Scheid DC, Logue EE, Iverson DC, et al. Does family practice at residency teaching sites reflect community practice? J Fam Pract 1993;37:555-63.

24. Wells KB, Stewart A, Hays RD, Burnam A, Rogers $W$, Daniels $M$, et al. The functioning and well-being of depressed patients. Results from the Medical Outcomes Study. JAMA 1989;262:914-9.

25. Broadhead WE, Blazer DG, George LK, Tse CK. Depression, disability days, and days lost from work in a prospective epidemiologic survey. JAMA 1990; 264:2524-8. 